Przemysław Magielski ${ }^{1}$, Anna Szcześniak ${ }^{1}$, Karolina Obońska ${ }^{1}$, Wioleta Stolarek ${ }^{2}$, Iwona Świątkiewicz ${ }^{1}$, Adam Sukiennik' ${ }^{1}$, Zofia Grąbczewska ${ }^{1}$, Grzegorz Grześk ${ }^{2}$, Marek Koziński ${ }^{1}$, Jacek Kubica ${ }^{1}$

${ }^{1}$ Department of Cardiology and Internal Medicine, Ludwik Rydygier Collegium Medicum, Nicolaus Copernicus University, Bydgoszcz, Poland

2Department of Pharmacology and Therapy, Ludwik Rydygier Collegium Medicum, Nicolaus Copernicus University, Bydgoszcz, Poland

\title{
Impact of prior statin therapy on evaluation of the inflammatory process and cortisol concentration in patients with the first ST-segment elevation myocardial infarction undergoing coronary angioplasty with bare metal stent implantation
}

\author{
Corresponding author: \\ Przemysław Magielski, MD \\ Department of Cardiology and Internal \\ Medicine, \\ Ludwik Rydygier Collegium Medicum \\ Nicolaus Copernicus University, \\ Sklodowskiej-Curie Street No. 9 , \\ 85-094 Bydgoszcz, Poland \\ Phone: + 48525854023 \\ Fax: +48525854024 \\ E-mail: przemyslaw.magielski@wp.pl
}

Medical Research Journal 2016; Volume 1, Number 1, 28-36 10.5603/MRJ.2016.0005 Copyright (C) 2016 Via Medica ISSN 2451-2591

\begin{abstract}
Introduction. The aim of the current study was to verify the impact of statin therapy on evaluation of the inflammatory process and cortisol concentration in patients with the first episode of ST-segment elevation myocardial infarction undergoing coronary angioplasty with bare metal stent implantation.

Material and methods. The study was designed as a prospective, single-center cohort study, with a total number of 200 patients enrolled between 2005 and 2008

Results. Seventeen patients with ongoing statin therapy and 167 patients without those agents underwent PPCl with BMS implantation. The cortisol concentration on admission was significantly lower in statin therapy subgroup - median $14.9 \mu \mathrm{g} / \mathrm{dL}$ (9.5-23.3 IQR) vs. 28,1 $\mu \mathrm{g} / \mathrm{dL}$ (17.2-39.9 IQR) for patients without lipid lowering drug, $p=0.01$. The level of cortisol after $23 \mathrm{~h}$ was also significantly lower in statin receiving subgroup: $10.4 \mu \mathrm{g} / \mathrm{dL}$ (8.3-19 IQR) vs. $17.3 \mu \mathrm{g} / \mathrm{dL}$ (10.1-25.9 IQR) adequately, $\mathrm{p}=0.021$. Those two groups did not differ significantly in relation to CRP, IL-6, IL-10 concentrations and to anti-inflammatory cytokine ratio [IL-6/L-10] on admission, after $24 \mathrm{~h}$ and at discharge. Significant differences were observed in the concentrations of $\mathrm{CTnl}$ and activities of CK and CK-MB.

Conclusions. Ongoing statin therapy before an episode of myocardial infarction has an influence on cortisol concentration and cardiac markers. No significant effect on serum levels of cytokines has been observed. Key words: inflammation, CRP, IL-6, IL-10, cortisol, cTnl, CK-MB, myocardial infarction, bare metal stent, statins, STEMI, primary $\mathrm{PCl}$, coronary angioplasty
\end{abstract}

Med Res J 2016; 1 (1): 28-36

\section{Introduction}

Over the past few years, an increased interest in the course of the inflammatory process associated with the onset and implemented treatment of acute coronary syndromes has been observed. Many factors that can have influence on the course of the acute coronary syndrome (ACS), effectiveness of treatment and the prognosis have been described. There are only a few studies referring to the analysis of the inflammatory process in a large homogeneous group of patients with the first episode of myocardial infarction undergoing primary coronary angioplasty with stent implementation. The relationship between the humoral pro- and anti-inflammatory response and factors associated with the performance of primary angioplasty procedures are still not fully understood. Understanding the mechanisms related to the course of acute ischemia and reperfusion may help to identify groups of patients at the highest risk and improve the effectiveness of treatment.

Low serum cortisol concentrations have been associated with adverse prognosis in critical illness of 
diverse etiology. There are only few previous studies on the association between cortisol concentration and prognosis after acute myocardial infarction and results are conflicting [1-6].

The aim of the current study was to verify the impact of statin therapy on the evaluation of inflammatory process, cortisol level and cardiac markers in patients with the first episode of ST-segment elevation myocardial infarction undergoing coronary angioplasty with bare metal stent implantation.

\section{Methods}

\section{Study design and participants}

The study was designed as a prospective, single-center cohort study with 200 patients enrolled. All of the patients were hospitalized in the Cardiology and Internal Diseases Department of the University Hospital No. 1 in Bydgoszcz due to the first episode of ST-elevation myocardial infarction. Patients were recruited between $1^{\text {st }}$ November 2005 and $1^{\text {st }}$ November 2008. All of the recruited patients underwent coronary angiography. Based on angiography findings: 6 patients underwent primary coronary angioplasty without stenting, 1 patient was diagnosed with Takotsubo cardiomyopathy, 9-patients underwent primary $\mathrm{PCl}$ with drug eluting stent implantation (DES), and bare metal stents (BMS) were implanted in the remaining 184 patients. Only 17 patients out of the whole study population were previously treated with statins.

Myocardial infarction was diagnosed based on the occurrence of clinical symptoms (typical chest pain) and ECG changes: ST-segment elevation $>2 \mathrm{~mm}$ in the precordial leads and $>1 \mathrm{~mm}$ in the limb leads. Standard physical examination, laboratory tests, electrocardiography and echocardiography were performed during hospitalization. In the analyzed population, selected markers of inflammation were determined: on admission to the hospital, after 24 hours of hospitalization and at discharge. Three months after hospitalization every patient was closely inspected.

Exclusion criteria were: age $>80$ years, heart failure in class III or IV according to NYHA, SBP > $200 \mathrm{~mm} \mathrm{Hg}$ and/or DBP > $100 \mathrm{~mm} \mathrm{Hg}$, cardiomyopathies, hemodynamically significant valvular heart disease or history of valvular cardiac surgery, previous $\mathrm{PCl}$ or $\mathrm{CABG}$, electrical stimulation of the heart, advanced chronic obstructive pulmonary disease, cancer, severe disease of other organs, prior surgery within 2 months, thrombocythopenia with platelet count $<100,000 / \mathrm{mm}^{3}$, the creatinine clearance $>2 \mathrm{mg} / \mathrm{dL}$ or dialysis, arteriosclerosis obliterans of the lower limbs, clinically overt infection, alcohol abuse, statement when the collaboration with the patient was impossible. The study was approved by the institutional review board and independent ethics committee. All patients enrolled in the study signed informed consent forms.

\section{Procedures}

Coronary angiography and percutaneous transluminal coronary angioplasty (PTCA) were performed using standard technique with the access from the femoral artery. Non-ionic contrast agents were used. The presence of residual stenosis of $20 \%$ of the reference segment diameter or lack of stenosis were treated as optimal treatment outcomes. Patients received $0.3 \mathrm{mg}$ of nitroglycerin intracoronary if the blood pressure allowed. All angiograms were evaluated by two independent invasive cardiologists - they had no access to clinical, electrocardiographic and echocardiographic data. The flow in the vessel was assessed by TIMI (Thrombolysis in Myocardial Infarction) and TIMI frame count (TFC) scores.

After the procedure, all patients received: clopidogrel (75 mg/day), acetylsalicylic acid (75 mg/day) and simvastatin (40 mg/day). In addition, in the majority of patients throughout the study period, ACEl and B-blocker in doses adapted to the value of blood pressure and heart rate (Tab. 1) were used.

\section{Laboratory tests}

Standard biochemical tests in patients with acute MI (BNP, complete blood cell count, CRP, electrolytes, creatinine clearance, lipids, fibrinogen, APTT, INR, HBs Ag, anti-HCV, blood group, BUN, glycaemia, $\mathrm{HbA}_{1 \mathrm{c}}$, lipid levels) were performed: on admission to the hospital, after 24 hours and at discharge. Cardiac markers (CK, CK-MB, Thl) on admission and after 6, 12 and $12 \mathrm{~h}$. Determination of cytokines (II-6, II-10) was scheduled as follows: on admission, after 24 hours of hospitalization, at discharge from hospital; cortisol concentration was assessed on admission, after 8 and 23 hours. In order to standardize the tests, in the first ten patients, blood samples were taken from the antecubital vein and femoral artery before angiography. The results showed no significant differences between the concentrations of cytokines assayed from both of the vessels, so all the blood samples, during the study period, were taken from antecubital vein. From every patient, $10 \mathrm{~mL}$ of blood was collected into citrate tubes, and then centrifuged for 20 minutes at $3000 \mathrm{rpm}$. The centrifuged plasma was frozen at $<-70^{\circ} \mathrm{C}$ and stored until the analysis was performed. The tests were performed using CBA Flex Sets tests (Becton Dickinson, Franklin Lakes, USA).

\section{Electrocardiography and echocardiography}

The standard 12-lead, resting electrocardiogram was performed at admission, before coronary angiography and before discharge. At discharge, transthoracic 
Table 1. Baseline patient characteristics

\begin{tabular}{|c|c|c|c|}
\hline $\begin{array}{l}\text { Population } \\
(n=184)\end{array}$ & $\begin{array}{c}\text { Statin (+) } \\
(n=17) \\
\text { Median (IQR) n (\%) }\end{array}$ & $\begin{array}{c}\text { Statin (-) } \\
(\mathrm{n}=167) \\
\text { Median (IQR) n (\%) }\end{array}$ & $\mathbf{p}$ \\
\hline \multicolumn{4}{|l|}{ On admission: } \\
\hline Age (years) & $63(51-68)$ & $55(50-62)$ & ns \\
\hline BMI $\left[\mathrm{kg} / \mathrm{m}^{2}\right]$ & $28.26(26.84-29.11)$ & $26.31(24.11-29.06)$ & ns \\
\hline Abdominal circumference $[\mathrm{cm}]$ & $105.0(96.5-110.0)$ & $98.5(90.0-106.0)$ & $p=0.033$ \\
\hline Glycaemia [mmol/L] & $7.11(6.22-9.06)$ & $7.61(6.72-9.22)$ & ns \\
\hline $\mathrm{HbA}_{1 \mathrm{c}}(\%)$ & $6.1(5.5-6.9)$ & $6.0(5.6-6.6)$ & ns \\
\hline Creatinine level $[\mu \mathrm{mol} / \mathrm{L}]$ & $79.56(70.72-88.4)$ & $83.98(76.91-97.24)$ & ns \\
\hline $\operatorname{LVEF}(\%)$ & $46.0(43.0-49.9)$ & $45.0(40.0-50.0)$ & ns \\
\hline BNP [pg/mL] & $109.2(47.6-146.7)$ & $47.1(25.3-85.8)$ & ns \\
\hline BNP at discharge $[\mathrm{pg} / \mathrm{mL}]$ & $124.1(37.4-169.1)$ & $114.0(69.9-215.9)$ & ns \\
\hline Male gender & $13(76.47 \%)$ & $129(77.25 \%)$ & ns \\
\hline Hypertension & $9(52.94 \%)$ & $64(38.32 \%)$ & ns \\
\hline Diabetes mellitus & $4(23.53 \%)$ & $22(13.17 \%)$ & ns \\
\hline Current smokers or history of smoking & $9(52.94 \%)$ & $114(68.26 \%)$ & ns \\
\hline Family history of CVD & $2(11.76 \%)$ & $36(21.56 \%)$ & ns \\
\hline Location of AMI anterior & $6(35.29 \%)$ & $68(40.72 \%)$ & ns \\
\hline Angina prior AMI (CCS I-IV) & $12(70.59 \%)$ & $13(44.83 \%)$ & ns \\
\hline TMPG 3 & $12(70.59 \%)$ & $77(46.11 \%)$ & ns \\
\hline \multicolumn{4}{|l|}{ Lipidogram [mmol/L]: } \\
\hline Total cholesterol & $4.47(4.01-5.84)$ & $5.82(5.17-6.57)$ & $p=0.007$ \\
\hline LDL & $2.79(2.28-3.75)$ & $3.8(3.31-4.60)$ & $p<0.001$ \\
\hline HDL & $1.37(1.19-1.45)$ & $1.31(1.16-1.53)$ & ns \\
\hline TG & $0.75(0.49-1.56)$ & $1.02(069-1.64)$ & ns \\
\hline \multicolumn{4}{|l|}{ At discharge: } \\
\hline LAD — target vessel & $6(35.29 \%)$ & $71(42.51 \%)$ & ns \\
\hline Stents 1 vs. $2 / 3$ & $2(11.76 \%)$ & $30(11.98 \%)$ & ns \\
\hline Multivessel CAD & $10(58.82 \%)$ & $100(59.88 \%)$ & ns \\
\hline TIMI 0 before $\mathrm{PCI}$ & $4(23.53 \%)$ & $93(55.69 \%)$ & $p=0.01$ \\
\hline TIMI 3 after $\mathrm{PCl}$ & $17(100 \%)$ & 155 (92.81\%) & ns \\
\hline Ilb/Illa receptors blocker & $1(5.882 \%)$ & $44(26.35 \%)$ & $p=0.033$ \\
\hline
\end{tabular}

IQR — interquartile range; BMI — body mass index; LVEF — ventricular ejection fraction; BNP — brain natriuretic peptide; CVD — cardiovascular diseases; AMI - acute myocardial infarction; TMPG — TIMI myocardial perfusion grade; TIMI — thrombolysis in myocardial infarction; LDL — low-density lipoprotein; HDL — high-density lipoprotein; TG — triglycerides; LAD — left artery descending

echocardiography, according to the protocol recommended by the American Society of Echocardiography, was also performed.

\section{Statistical analysis}

The statistical analysis was carried out using the Statistica 10 package. Due to fact that data distribution was different from normal, based on the Shapiro-Wilk W-test and the Kolmogorov-Smirnov, the results are pre- sented as the median value and IQ range for quantitative parameters and as percentage of the population for qualitative parameters. Significance of the differences was evaluated using non-parametric Mann-Whitney U-test or Kruskal-Wallis ANOVA. The Wilcoxon signed rank test was used to evaluate dependent samples and Spearman's rank test for correlation. The $\chi^{2}$ test (and with the Yates correction if needed) was used for qualitative variables. A difference was considered significant at $p<0.05$. 
Table 2. Drugs prior to acute myocardial infraction (AMI)

\begin{tabular}{lccc}
\hline Drugs & $\begin{array}{c}\text { Statin (+) } \\
(\mathbf{n}=\mathbf{1 7}) \\
\text { Median (IQR) } \mathbf{n}(\%)\end{array}$ & $\begin{array}{c}\text { Statin (-) } \\
(\mathbf{n}=\mathbf{1 6 7 )} \\
\text { Median (IQR) } \mathbf{n}(\%)\end{array}$ & $\mathbf{p}$ \\
\hline Aspirin & $7(41.18 \%)$ & $7(4.19 \%)$ & $\mathrm{p}<0.001$ \\
ACE inhibitors/AT1 blockers & $6(35.294 \%)$ & $20(11.98 \%)$ & $\mathrm{p}=0.020$ \\
B-blockers & $5(29.41 \%)$ & $11(6.59 \%)$ & $\mathrm{p}=0.008$ \\
Calcium channel blocker & $5(29.41 \%)$ & $10(5.995 \%)$ & $\mathrm{p}=0.005$ \\
Diuretics & $1(5.88 \%)$ & 0 & $\mathrm{~ns}$ \\
\hline
\end{tabular}

ACE - angiotensin-converting enzyme

Table 3. Comparison of the levels of cardiac markers concentrations at subsequent time endpoints in two subgroups: patients untreated and treated with a statin

\begin{tabular}{|c|c|c|c|}
\hline $\begin{array}{l}\text { Population } \\
(n=184)\end{array}$ & $\begin{array}{c}\text { Statin (+) } \\
(\mathrm{n}=17) \\
\text { Median (IQR) n (\%) }\end{array}$ & $\begin{array}{c}\text { Statin (-) } \\
(\mathrm{n}=167) \\
\text { Median (IQR) n (\%) }\end{array}$ & $\mathbf{p}$ \\
\hline \multicolumn{4}{|c|}{ On admission: } \\
\hline CPK & 204 (134-345) & $169(106-315)$ & ns \\
\hline CK-MB & $31(18-53)$ & $25(18-42)$ & ns \\
\hline Tnl & $0.35(0.09-1.18)$ & $0.26(0.06-1.01)$ & ns \\
\hline \multicolumn{4}{|l|}{$6 \mathrm{~h}$ after $\mathrm{PCl}:$} \\
\hline CPK & 642 (436-2041) & 1849 (824-3596) & ns \\
\hline CK-MB & $82(62-216)$ & 257 (125-437) & $p=0.003$ \\
\hline Tnl & $15.42(6.72-43.35)$ & $48.17(12.85-50.0)$ & $p=0.027$ \\
\hline \multicolumn{4}{|c|}{$12 \mathrm{~h}$ after $\mathrm{PCl}:$} \\
\hline CPK & $642(480-1707)$ & $1645(782-2770)$ & $p=0.009$ \\
\hline CK-MB & $81(60-151)$ & 206 (119-335) & $p=0.001$ \\
\hline \multicolumn{4}{|c|}{$24 \mathrm{~h}$ after $\mathrm{PCl}$ : } \\
\hline CPK & $351(323-1104)$ & $1000(506-1631)$ & $p=0.01$ \\
\hline CK-MB & $45(40-73)$ & 99 (59-154) & $p=0.001$ \\
\hline
\end{tabular}

CPK — creatine phosphokinase; CK-MB — MB isoenzyme of creatine kinase; Tnl — cardiac-specific troponin I

\section{Results}

\section{Patients and procedures}

Between March 25, 2005 and May 7, 2007, a total number of 200 patients, from our center, who had ST-segment elevation myocardial infarction and undergone primary $\mathrm{PCl}$ with bare metal stent, were included into the study.

Before the hospitalization, only 17 patients were treated with statins $(9.24 \%) ; 13$ patients had received simvastatin and 4 atorvastatin.

Those two subgroups did not differ in terms of the location of the myocardial infarction, the number of infarct related vessels and flow rates in the target vessel (Tab. 1). However, the percentage of patients with TIMI 0 before stent implantation was higher in the group not receiving statins $(55.69 \%$ vs. $23.53 \%, p=0.01)$. Population treated with statins was characterized by a larger abdominal circumference (median $105.0 \mathrm{vs} .98 .5 \mathrm{~cm}, \mathrm{p}=0.033$ ), lower levels of total cholesterol (median 4.47 vs. $5.82 \mathrm{mmol} / \mathrm{L}, \mathrm{p}=0.007$ ) and LDL cholesterol (median 2.79 vs. $3.80 \mathrm{mmol} / \mathrm{L}$, $p<0.001$ ). Significant differences in drug patterns prior AMI were noted at admission (Tab. 2).

Interesting differences in cardiac markers profiles were identified in both subgroups. In spite of comparable activity of CK (204 vs. $169 \mathrm{U} / \mathrm{L})$, CK-MB (31 vs. $26 \mathrm{U} / \mathrm{L}$ ) and cTnl (0.35 vs. $0.26 \mu \mathrm{g} / \mathrm{L}$ ) on admission, the higher levels of CK-MB and Tnl were observed after $6 \mathrm{~h}, 12 \mathrm{~h}$ and $24 \mathrm{~h}$ in population not previously treated by statin (Tab. 3, Fig. 1).

It was also noted that in statin group maximum cTnl levels (median 15 vs. $30.47 .04 \mu \mathrm{g} / \mathrm{L}, \mathrm{p}<0.022$ ) and maximum CK-MB (median 54.00 vs. $103.00 \mathrm{U} / \mathrm{L}$, $\mathrm{p}=0.010$ ) were significantly lower. 


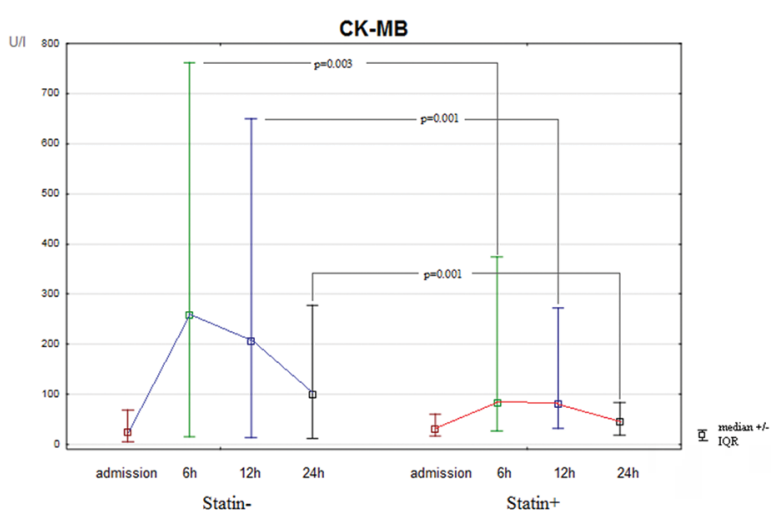

Figure 1. Differences in concentration of $M B$ isoenzyme of CK (CK-MB) in two subgroups of patients: treated and not treated with statin before hospitalization during the first day of hospitalization

In the whole analyzed population, maximum cTnl concentration and CK-MB maximum activity significantly correlated with CRP after $24 \mathrm{~h}(\mathrm{r}=0.454, \mathrm{p}<0.001$; $r=0.472, p<0.001$ respectively) and CRP level at discharge $(r=0.325, p<0.001 ; r=0.363, p<0.001$ respectively) but no differences between both groups were found.

\section{Comparative analysis of concentrations and ratios of cytokines}

CRP level. The level of C-reactive protein on admission to the hospital (Tab. 4) was: $1.57 \mathrm{mg} / \mathrm{L}$ (IQR $4.62)$ vs. $1.84 \mathrm{mg} / \mathrm{L}$ (IQR 9.38) for previously treated and not treated with statins respectively. CRP level after 24 hours: median $9 \mathrm{mg} / \mathrm{L}$ (IQR 48.19) vs. $10.59 \mathrm{mg} / \mathrm{L}$ (IQR 107.1) adequately $(p=0.255)$. The two groups differed significantly in CRP concentration only at discharge: median $7.24 \mathrm{mg} / \mathrm{L}$ (IQR 30.44) for patients treated vs. $11.13 \mathrm{mg} / \mathrm{L}$ (IQR 72.66) for those not treated with HMG-Co A inhibitors, $\mathrm{p}=0.018$.

Concentration changes patterns in both groups were similar. Significant increase of CRP concentration between on admission vs. after $24 \mathrm{~h}$ was observed $(p<0.05)$ and non-significant change occurred from $24 \mathrm{~h}$ up to at discharge (Fig. 2).

Interleukin 6. The concentrations of pro-inflammatory IL-6 on admission to the hospital were similar between the subgroups: median $14.359 \mathrm{pg} / \mathrm{mL}$ (IQR 85.277) for patients treated vs. $12.462 \mathrm{pg} / \mathrm{mL}$ (IQR 1498.684) for those not treated with statin, $p=0.093$. IL-6 levels after 24 hours were as follows: median $25.958 \mathrm{ng} / \mathrm{mL}$ (IQR 54.085) vs. $25.69 \mathrm{ng} / \mathrm{mL}$ (IQR 582.633) for previously treated and not treated with HMG-Co A inhibitors $(p=0.948)$. The level of cytokine at discharge was: $12.706 \mathrm{ng} / \mathrm{mL}$ (IQR 65.055) vs. 16,203 ng/mL (IQR663.365) respectively. Only in one patient not treated previously with statin, significant increase of IL-6 concentration between on admission vs. after $24 \mathrm{~h}(\mathrm{p}<0.05)$ and decrease from $24 \mathrm{~h}$ till discharge $(p<0.05)$ was identified (Fig. 3$)$.

Interleukin 10. The concentration of anti-inflammatory IL-10 on admission was significantly lower among patients form the statin therapy subgroup - median $12.93 \mathrm{pg} / \mathrm{mL}$ (IQR 97.305) vs. $15.495 \mathrm{pg} / \mathrm{mL}$ (IQR 1115.259) for patients without lipid lowering drug, $p=0.035$. IL-10 level after 24 hours was as follows: median $14.635 \mathrm{pg} / \mathrm{mL}$

Table 4. Comparison of the levels of acute phase proteins and cortisol at subsequent time endpoints in two subgroups: patients untreated and treated with statin

\begin{tabular}{|c|c|c|c|}
\hline $\begin{array}{l}\text { Population } \\
(n=184)\end{array}$ & $\begin{array}{c}\text { Statin (+) } \\
(n=17) \\
\text { Median (IQR) }\end{array}$ & $\begin{array}{c}\text { Statin (-) } \\
(n=167) \\
\text { Median (IQR) }\end{array}$ & $\mathbf{p}$ \\
\hline CRP on admission & $1.57(0.87-2.37)$ & $1.84(1.02-3.27)$ & ns \\
\hline CRP $24 \mathrm{~h}$ & $9(5.14-10.8)$ & 10.59 (5.85-21.2) & ns \\
\hline CRP at discharge & $7.24(5.48-11.26)$ & $11.13(5.27-17.75)$ & $p=0.018$ \\
\hline IL-6 on admission & 14.359 (6.285-26.335) & $12.462(7.944-26.763)$ & ns \\
\hline IL-6 $24 \mathrm{~h}$ & $25.958(12.396-0.625)$ & 25.69 (13.841-4.945) & ns \\
\hline IL-6 at discharge & $12.706(2.19-9.128)$ & $16.203(8.425-29.157)$ & ns \\
\hline IL-10 on admission & $12.93(10.809-26.537)$ & 15.495 (9.396-30.649) & $p=0.01$ \\
\hline IL-10 $24 \mathrm{~h}$ & 14.635 (10.955-21.364) & 15.693 (8.951-29.293) & ns \\
\hline IL-10 at discharge & $8.766(2.682-27.804)$ & 14.79 (5.452-23.628) & ns \\
\hline Cortisol on admission & $14.9(9.5-23.3)$ & $28.1(17.2-39.9)$ & $p=0.010$ \\
\hline Cortisol $8 \mathrm{~h}$ & $17.4(15.5-20.8)$ & $20(15.6-24)$ & $p=0.220$ \\
\hline Cortisol $23 \mathrm{~h}$ & $10.4(8.3-19)$ & $17.3(10.1-25.9)$ & $p=0.021$ \\
\hline
\end{tabular}

CRP - C-reactive protein; IL — interleukin 

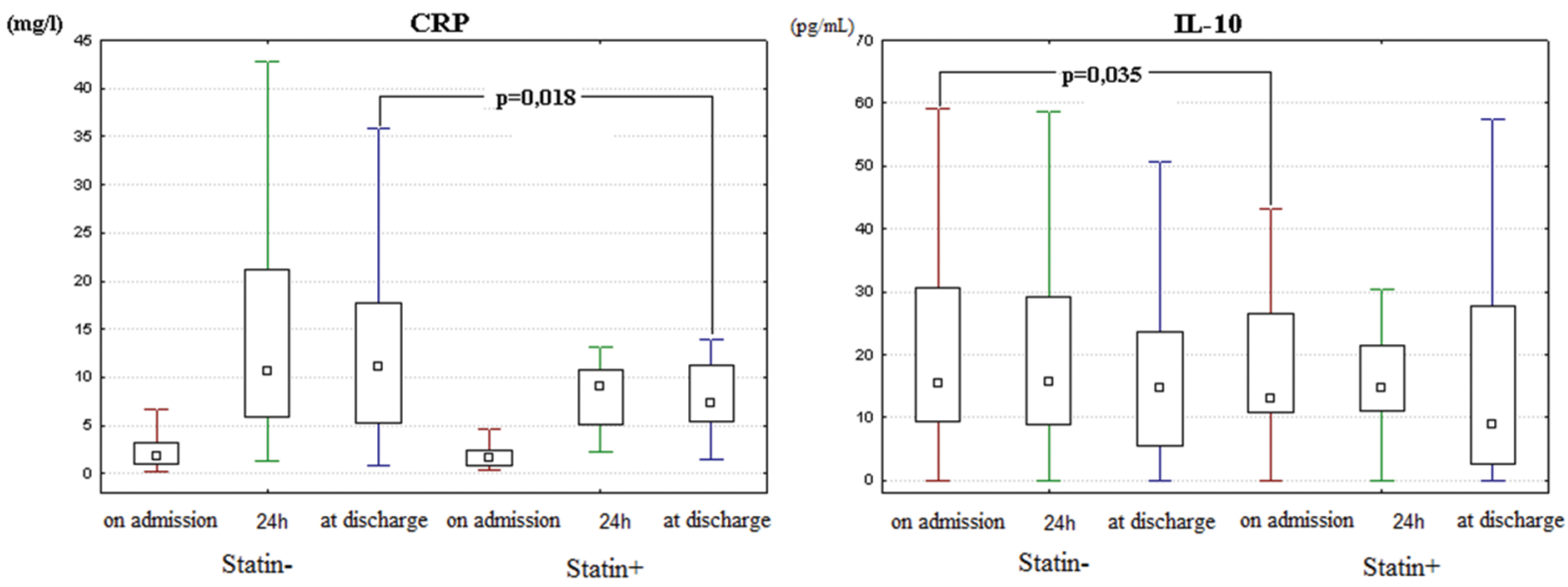

Figure 2. Dynamics of changes in the concentrations of cytokines at the subsequent measurement endpoints in two subgroups of patients: treated and not treated with statin before hospitalization (on admission, $24 \mathrm{~h}$ after primary PCl, at discharge)

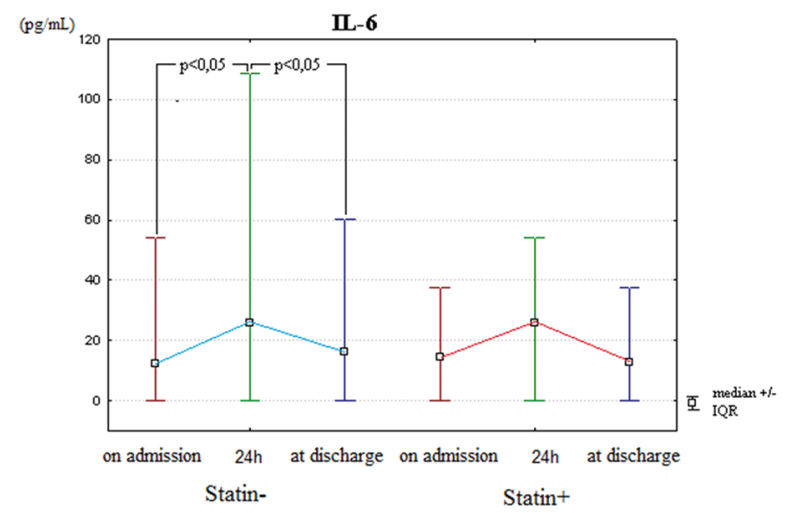

Figure 3. Dynamics of changes in the concentrations of IL-6 at the subsequent measurement endpoints in two subgroups of patients: treated and not treated with statin before hospitalization (on admission, 24 hours after primary $\mathrm{PCl}$, at discharge)

(IQR 68.848) vs. $15.693 \mathrm{pg} / \mathrm{mL}$ (IQR 1428.645) for previously treated and not treated with statin $(p=0.399)$. The level of cytokine at discharge did not differ significantly but was greater in the statin subgroup: $8.766 \mathrm{pg} / \mathrm{mL}$ (IQR 57.383) vs. 14.792 (IQR 563.043).

Proportion of cytokines. All the comparisons of the proportion of the levels of cytokines in subsequent time endpoints did not reach statistical significance. The ratio between IL- 6 and IL-10 on admission was: 0.897 median (IQR 3.698) vs. 0.807 (IQR 26.543) for patients with and without statin therapy before admission to the hospital ( $p=0.341)$; after 24 hours - 1.663 (IQR 2.199) vs. 1.392 (IQR 15.804) ( $p=0.414)$; at discharge it was -1.145 (IQR 4.738) vs. 1.045 (IQR 24.968) ( $p=0.497$ ).
Cortisol concentration. The concentration of serum cortisol on admission was significantly lower among patients in the statin therapy subgroup (Tab. 4) - median $14.9 \mu \mathrm{g} / \mathrm{dL}$ (IQR 13.8) vs. 28.1 $\mu \mathrm{g} / \mathrm{dL}$ (IQR 22.7) for patients without statin therapy, $p=0.01$. Cortisol level (Fig. 4) after 8 hours was: in the patients previously treated with statins - median 17,4 $\mu \mathrm{g} / \mathrm{dL}$ (IQR 5.3) vs. $20 \mu \mathrm{g} / \mathrm{dL}$ (IQR 8.4) in those not treated with statins $(p=0.22)$. The level of steroid at discharge was significantly lower in patients who received statin previously: $10.4 \mu \mathrm{g} / \mathrm{dL}$ (IQR 10.7) vs. $17.3 \mu \mathrm{g} / \mathrm{dL}$ (IQR $15.8)$ for patients without statin therapy before hospitalization, $\mathrm{p}=0.021$.

Comparative analysis of pre-specified subgroups: patients with hyperlipidemia treated with statin, patients with hyperlipidemia without lipid lowering drugs, patients without hyperlipidemia

Close inspection in the pre-specified subgroups has shown a lack of disparity between concentration of CRP, concentration of IL- 6 and IL-10. It also revealed significant differences in cortisol level on admission and non-significant but visible at 8 and 23 hours after admission. Cortisol concentration on admission and after 23 hours was meaningfully lower in patients with prior lipid lowering therapy (on admission - median $14.9 \mu \mathrm{g} / \mathrm{dL}$ (IQR 9.5-23.3) for patients on statin therapy before episode of Ml vs. $29.4 \mu \mathrm{g} / \mathrm{dL}$ (IQR 22.4) for patients with hyperlipidemia and without statins vs. $27.95 \mu \mathrm{g} / \mathrm{dL}$ (IQR 22.2) for patients without lipid disturbances, $\mathrm{p}=0,035$; after $8 \mathrm{~h}-17.4 \mu \mathrm{g} / \mathrm{dL}$ (IQR 5.3) vs. $22.4 \mu \mathrm{g} / \mathrm{dL}$ (IQR 6.3) vs. $19.75 \mu \mathrm{g} / \mathrm{dL}$ (IQR 9.7) respectively, $\mathrm{p}=0.055$; after $23 \mathrm{~h}-10.4 \mu \mathrm{g} / \mathrm{dL}$ (IQR 
10.7) vs. $16.0 \mu \mathrm{g} / \mathrm{dL}$ (IQR 16.16) vs. $17.35 \mu \mathrm{g} / \mathrm{dL}$ (IQR 15.3) respectively, $p=0.680$ ).

\section{Discussion}

Statins are the first line drugs in primary and secondary prevention of atherosclerosis [7-8]. The high efficacy of these drugs results from widely documented pleiotropic effects, including its anti-inflammatory activity [9-10]. The mechanism of action of statins and modulation of the inflammatory process is not fully understood [11], but a number of experimental and clinical studies confirm the beneficial effect of these drugs on inflammation process. One of the postulated routes of statins action is inhibition of activation NF-kappa B protein, which is one of the elements of the relay route for C-reactive protein [12].

A study by Hoffman has shown that statin pretreatment in patients with AMI was associated with decreased systemic inflammation and better perfusion after primary angioplasty of the infarct-related artery [13]. In his study of 253 patients, divided into two groups: with statin pretreatment $(n=86)$ and control $(n=167)$, pretreatment was associated with a lower frequency of increased C-reactive protein ( $\geq 5 \mathrm{mg} / \mathrm{L}$ ) on admission compared with the control group ( $48 \%$ vs. $64 \% ; p=0.019$ ). In our study, the two groups differed significantly in CRP concentration only at discharge.

Very interesting findings were observed in the study evaluating the expression of CRP directly from the material taken from the plaque during $\mathrm{PCl}$ (atherectomy in a vessel with stenosis $>80 \%$ ) [14]. Previous therapy with statins in patients with ACS was associated with significantly lower expression of CRP within the lesion $(p=0.009)$. This effect was the same for all the types and doses of statins. However, there is a variation among the HMG-CoA inhibitors in their properties. The analysis of Prove IT-TIMI22 study indicated that there are differences in the effectiveness of different types of statins [15]. At the comparable levels of CRP at the beginning of the study $(12.2 \mathrm{mg} / \mathrm{L}$ for atorvastatin and $11.9 \mathrm{mg} / \mathrm{L}$ for pravastatin, $p=0.60$ ) there were significant differences in the level of $\mathrm{C}$-reactive protein after 30 days ( 1.6 vs. $2.3 \mathrm{mg} / \mathrm{L})$ and after 4 months $(1.3 \mathrm{vs} .2 .1 \mathrm{mg} / \mathrm{L}$ in favor of atorvastatin ( $p$ for all differences < 0.001.) A study conducted by Heart Protection Study Collaborative Group in patients with high cardiovascular risk, receiving a placebo or simvastatin (in a dose of $40 \mathrm{mg}$ ), has shown no significant relationship between baseline CRP and reduction of the risk of cardiovascular events in the 5-year follow-up (vascular events: $p=0.41$, coronary events $p=0.81$ ) [16]. Thus, the future studies to discover which statins have

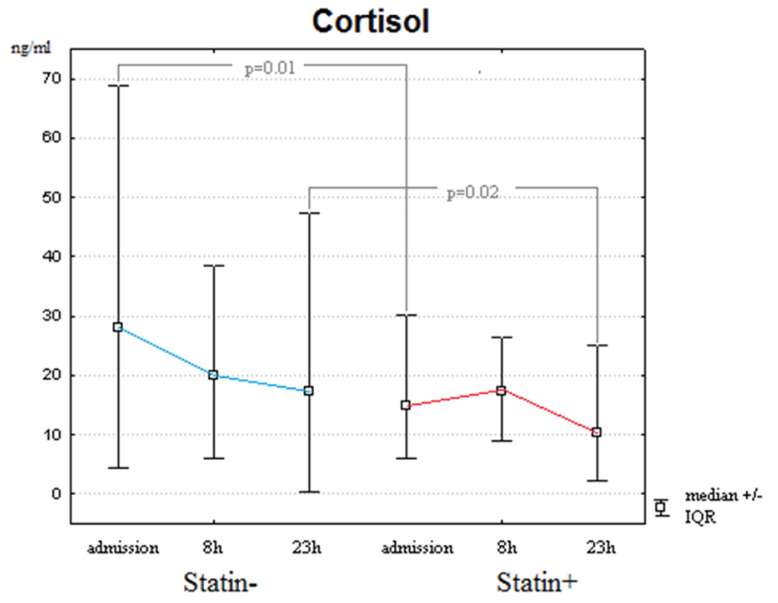

Figure 4. Dynamics of changes in the concentrations of cortisol in two subgroups of patients: treated and not treated with statin before hospitalization (on admission, 8 and $23 \mathrm{~h}$ after primary $\mathrm{PCl}$ )

the best potential to reduce the CRP and LDL-cholesterol levels are needed.

\section{Cytokines}

Li et al., in their very interesting work, analyzed the changes in the concentrations of cytokines in patients with unstable angina and receiving 20 or $80 \mathrm{mg}$ of simvastatin [17]. It has been reported that in the group of $20 \mathrm{mg} / \mathrm{d}$, CRP decreased significantly from $5.6 \mathrm{mg} / \mathrm{L}$ at admission to $4.0 \mathrm{mg} / \mathrm{L}$ on the $14^{\text {th }}$ day of the study ( $28 \%$ reduction of the basic level of CRP). Furthermore, in the group that received $80 \mathrm{mg}$ of simvastatin, the value of CRP of $5.7 \mathrm{mg} / \mathrm{L}$ at admission decreased significantly to $3.8 \mathrm{mg} / \mathrm{L}$ (33\% reduction compared with the baseline level). The concentration of IL-10 in the group of $20 \mathrm{mg} / \mathrm{d}$ of simvastatin increased from $16.2 \mathrm{pg} / \mathrm{mL}$ at admission to $22.4 \mathrm{pg} / \mathrm{mL}$ on day $14(\mathrm{p}<0.001)$ and, by analogy, from $15.8 \mathrm{pg} / \mathrm{mL}$ to $28.5 \mathrm{pg} / \mathrm{mL}$ in patients treated with the dose of $80 \mathrm{mg} / \mathrm{d}(\mathrm{p}<0.001)$. The existence of significant inverse correlation between the concentrations of CRP and IL- 10 on day 14 (at $20 \mathrm{mg} / \mathrm{d}, \mathrm{p}<0.05$, for $80 \mathrm{mg} / \mathrm{d}, \mathrm{p}<0.01$ ) was also observed.

In our study the concentration and relative proportions of CRP, pro-inflammatory IL- 6 and anti-inflammatory IL-10 were measured. CRP and IL-10 were identified as significant markers of inflammation. An increase in the proportion of pro- and anti-inflammatory cytokines was observed as well. The level of anti-inflammatory IL-10 on admission to the hospital was significantly lower in statin users before MI. We found no difference in concentration of pro-inflammatory 
IL-6 among the subgroups. Decrease in the level of anti-inflammatory cytokines between 24 hours of hospitalization and discharge from the hospital was higher in patients with history of statin intake, but due to the low number of patients did not reached the statistical significance.

In the case of concentration of IL-6, the similar outcome was observed by Stefanadi et al., but in their study patients were treated with a different type of statin - atorvastatin. However, the study of Stefanadi et al. also confirmed the anti-inflammatory effect of low doses of atorvastatin [18]. The population of ST- elevation MI patients was treated with thrombolysis and atorvastatin (in dose $10 \mathrm{mg}$ for 6 weeks). The measurements of the levels of cytokine were performed 6 hours after admission to hospital, after thrombolysis, after one week and after 6 weeks. There were no differences in the baseline concentrations of IL- 6 , and this effect was maintained even after one week. In both groups, there was a decrease of cytokine after 6 weeks, but only in the group receiving statin this outcome was statistically significant $(p=0.014)$.

In the experimental model in rats, previously treated or untreated with atorvastatin for 4 weeks, myocardial infarction (LAD closure) was induced [19]. After a period of 4 weeks, subsequent echocardiography, ventriculography and measurements of the levels of IL-6, TNF $\alpha$ and IL-10 (in the serum and in the myocardium) were performed. The results have shown that the administration of statins has been associated with significantly lower levels of IL-6 and TNF $\alpha$ (for both $p<0.01$ ). Furthermore, the concentration of IL-10 was significantly higher ( $p<0.01$ ). TNF $\alpha /$ IL-10 ratio was significantly lower in the group receiving statins $(p<0.05)$.

\section{Cortisol}

Low serum cortisol concentrations have been associated with adverse prognosis in critical illness of diverse etiology. Previous studies of the association between cortisol concentration and prognosis after acute myocardial infarction are few and the results are conflicting. Zouaghi, in his study of just 34 patients, reported a negative association between cortisol concentration and the risk of death [1]. Only one study suggested that low cortisol concentration on admission is an adverse prognostic indicator in patients with acute MI [2]. By contrast, three small studies of between 22 to 70 patients, with few deaths, suggested increased risk of death among patients with high cortisol concentrations [3-5]. In our study, cortisol concentration was significantly lower in the subgroup previously treated with statins at almost every measurement time point. It is possible that there are subgroups of patients in whom either very high or very low cortisol level confers an adverse prognosis in acute myocardial infarction, as in a more heterogeneous critical illness [6].

Weir et al. in their study found that higher levels of aldosterone and cortisol were associated with greater medium-term LV remodeling when measured in the first few days after AMI in patients with LVSD but no evidence of heart failure. Aldosterone and cortisol were also related to larger infarct volumes at baseline and greater infarct remodeling over time [20].

It may be suspected that there is a correlation between stress, cortisol release and production of cytokines. Nijm found that IL- 6 is induced not only by inflammatory stimuli but also by acute stress, presumably via catecholamines [21]. In his study, the coronary artery disease patients showed a cortisol pattern that markedly differed from healthy controls. It involved a flatter diurnal slope and an attenuated cortisol response to acute stressors. Parallel to these findings, there was also a stress-induced increase in CRP that was specific to CAD patients.

Studies of basal and stimulated hormones have been used to evaluate steroidogenesis in subjects on hepatic hydroxymethylglutaryl coenzyme A (HMG-CoA) reductase inhibitors. In our study, most of the patients were on simvastatin therapy. The researchers found that simvastatin in doses of up to $80 \mathrm{mg} / \mathrm{d}$ has no effect on adrenal and gonadal steroid production [22-24].

\section{Limitations of the study}

Several limitations of our study should be acknowledged. First, the study has been designed in 2004 based on then current guidelines and the available methods of lab tests. The recruitment was carried out in 2005-2008. All patients included into the study had bare metal stent implanted in accordance with ESC standards. This strategy provides a high homogeneity of the population and at the same time made it impossible to compare the effect of the drug eluting stents, currently widely used, on the course of the inflammatory process. In order to precisely measure the onset of myocardial infarction we should reduce the time interval between the beginning of incidence and revascularization. The assessment of the changes dynamics in the ST segment and its resolution would be a valuable analysis in this case. Patients receiving statins prior to AMI were not a homogenous group (4 patients on atorvastatin and 13 on simvastatin). Moreover, dosage and treatment period had not been available in source documentation so full analysis was not possible.

Currently, it is also recommended to perform the CRP assay with a high sensitivity method (hs-CRP). It should also be noted that performing a serial analysis of the inflammatory parameters between primary $\mathrm{PCl}$ 
and 64 hours of hospitalization would be interesting for the study. The previously cited studies indicate that delayed peak of cytokines after approximately 48 hours is possible. Such change in the protocol of the study would allow to assess the dynamics of changes in the concentrations of cytokines - determine their maximum levels, the time to achieve the maximum level, and the time to return to the baseline. But the high costs of such procedure and nuisance for the patients made it impossible to perform.

To directly assess the impact of factors associated with $\mathrm{PCl}$ we also ought to take the blood samples from the aortic bulb, from the target coronary vessel right after the occlusion and from the coronary sinus, all in serial measurements. This project could help, by the index change between measuring points, to determine the place of synthesis and ejection of individual cytokines.

\section{Conclusions}

Statin therapy has a significant influence on cortisol level as well as on the profile of cardiac markers in patients with the first episode of ST-elevation myocardial infarction undergoing $\mathrm{pPCl}$ with bare metal stent implantation. Patients previously treated with statins had significantly lower level of cortisol on admission and after 23 hours. No differences in pro- and anti-inflammatory cytokines concentration were observed. Future studies are needed to determine the clinical significance of these findings.

\section{Conflict of interest}

The authors have no conflict of interest to disclose.

\section{Acknowledgments}

We would like to thank the patients who agreed to participate in this trial, the study contributors, and the investigators who recruited patients.

\section{References}

1. Zouaghi H, Savu L, Guerot C, Gryman R, Coulon A, Nunez EA. Total and unbound cortisol-, progesterone-, oestroneand transcortin-binding activities in sera from patients with myocardial infarction: Evidence for differential responses of good and bad prognostic cases. Eur J Clin Invest 1985; 15: 365-370.

2. Reynolds RM , Walker BR, Haw S et al. Low serum cortisol predicts early death after acute myocardial infarction. Crit Care Med 2010; 38: 973-975
3. Bain RJ, Fox JP, Jagger J, Davies MK, Litter WA, Murray RG. Serum cortisol levels predict infarct size and patient mortality. Int $J$ Cardiol 1992; 37: 145-150.

4. Nito I, Waspadji S, Harun S, Markum HM. Correlation between cortisol levels and myocardial infarction mortality among intensive coronary care unit patients during first seven days in hospital. Acta Med Indones 2004; 36: 8-14

5. Prakash R, Parmley WW. Horvat M, Swan HJ. Serum cortisol, plasma free fatty acids, and urinary cathecholamines as indicators of complications in acute myocardial infarction. Circulation 1972; 45: 736-745.

6. Rothwell PM Lawler PG. Prediction of outcome in intensive care patients using endocrine parameters. Crit Care Med 1995; 23:78-83.

7. Steg PG, James SK, Atar D. Task Force on the management of ST segment elevation acute myocardial infarction of the European Society of Cardiology (ESC). ESC Guidelines for the management of acute myocardial infarction in patients presenting with ST-segment elevation. Eur Heart J 2012; 33: 2569-2619.

8. Lenderink T, Boersma E, Gitt AK et al. Patients using statin treatment within $24 \mathrm{~h}$ after admission for ST-elevation acute coronary syndromes had lower mortality than non-users: a report from the first Euro Heart Survey on acute coronary syndromes. Eur Heart J 2006; 27: 1799-1804

9. Ridker PM, Danielson E, Fonseca FA et al. Rosuvastatin to prevent vascular events in men and women with elevated C-reactive protein. N Engl J Med 2008; 359: 2195-2207.

10. Kinlay S, Schwartz GG, Olsson AG et al. High-dose atorvastatin enhances the decline in inflammatory markers in patients with acute coronary syndromes in the MIRACL study. Circulation 2003; 108: 1560-1566.

11. Turner NA, Mughal RS, Warburton P, O'Regan DJ, Ball SG, Porter KE. Mechanism of TNFalpha-induced IL-1alpha, IL-1beta and IL-6 expression in human cardiac fibroblasts: effects of statins and thiazolidinediones. Cardiovasc Res 2007; 76: 81-90.

12. Wang HR, Li JJ, Huang $\mathrm{CX}$, Jiang $\mathrm{H}$. Fluvastatin inhibits the expression of tumor necrosis factor-alpha and activation of nuclear factor-kappaB in human endothelial cells stimulated by C-reactive protein. Clin Chim Acta 2005; 353: 53-60.

13. Hoffmann R, Haager $P$, Suliman $H$. Effect of statin therapy before Q-wave myocardial infarction on myocardial perfusion. Am J Cardiol 2008; 101: 139-143.

14. Andrié RP, Bauriedel G, Braun P, Hopp HW, Nickenig G, Skowasch $D$. Increased expression of $\mathrm{C}$-reactive protein and tissue factor in acute coronary syndrome lesions: Correlation with serum C-reactive protein, angioscopic findings, and modification by statins. Atherosclerosis. 2009; 202: 135-143.

15. Ridker PM, Cannon CP, Morrow D et al. C-reactive protein levels and outcomes after statin therapy. N Engl J Med 2005; 352: 20-28.

16. Heart Protection Study Collaborative Group. C-reactive protein concentration and the vascular benefits of statin therapy: an analysis of 20,536 patients in the Heart Protection Study. Lancet 2011; 377: 469-476.

17. Li J J, Li Y-S, Fang C-H et al. Effects of simvastatin within two weeks on anti inflammatory cytokine interleukin 10 in patients with unstable angina Heart. 2006; 92: 529-530.

18. Stefanadi E, Tousoulis D, Antoniades $C$ et al. Early initiation of low-dose atorvastatin treatment after an acute ST-elevated myocardial infarction, decreases inflammatory process and prevents endothelial injury and activation. Int J Cardiol. 2009; 133: 266-268.

19. Stumpf C, Petzi S, Seybold K et al. Atorvastatin enhances interleukin-10 levels and improves cardiac function in rats after acute myocardial infarction. Clin Sci (Lond) 2009; 116: 45-52.

20. Weir RA, Tsorlalis IK, Steedman T et al. Aldosterone and cortisol predict medium-term left ventricular remodeling following myocardial infarction. Eur J Heart Fail 2011; 13: 1305-1313.

21. Nijm J, Kristenson M, Olsson AG, Jonasson L. Impaired cortisol response to acute stressors in patients with coronary disease. Implications for inflammatory activity. J Intern Med 2007; 262: 375-384.

22. Candrina R, Balestrieri G, Salvi A, Di Stefano O, Spandrio S, Giustina G. Cortisol secretion in patients on simvastatin. Lancet 1990; 335: 53.

23. Mol Mi, Stalenhoef AF, Stuyt PM, Hermus AR, Demacker PN, Van T Laar A. Effects of inhibition of cholesterol synthesis by simvastatin on the production of adrenocortical steroid hormones and ACTH. Clin Endocrinol (Oxf) 1989; 31: 679-689.

24. Dobs AS, Schrott $H$, Davidson $\mathrm{MH}$ et al. Effects of high-dose simvastatin on adrenal and gonadal steroidogenesis in men with hypercholesterolemia. Metabolism 2000; 49: 1234-1238. 